\title{
SVEP1 IS IMPORTANT FOR MORPHOGENESIS OF LYMPHATIC SYSTEM: POSSIBLE IMPLICATIONS IN LYMPHEDEMA
}

S. Michelini, B. Amato, M. Ricei, R. Serrani, D. Veselenyiova,

S. Kenanoglu, D. Kurti, A. Dautaj, M. Baglivo, R. Compagna,

J. Krajcovic, M. Dundar, S.H. Basha, S. Priya, J.P. Belgrado, M. Bertelli

Department of Vascular Rehabilitation (SM), San Giuseppe Hospital Marino, Rome, Italy; Department of General and Geriatric Surgery (BA), University of Naples "Federico II", Naples, Italy; Division of Rehabilitation Medicine (MR,RS), Azienda Ospedaliero-Universitaria, Ospedali Riuniti di Ancona, Italy; University of Ss. Cyril and Methodius In Trnava, Department of Biology (DV,JK), Faculty of Natural Sciences, Trnava, Slovakia; MAGI Euregio (DV,SK,DK,MB,MB), Bolzano, BZ; Italy; Department of Medical Genetics (SK,MD), Faculty of Medicine, Erciyes University, Kayseri, Turkey; MAGI-Balkan (DK,AD), Tirana, Albania; EBTNA-Lab, Rovereto (AD,MB), TN, Italy; Department of Public Health (RC), Università Degli Studi di Napoli Federico II; Innovative Informatica Technologies (SHB,SP), Hyderabad, India; Free University of Bruxelles (JPB), Faculty of Exercise Sciences, Bruxelles Belgium; MAGI's Lab, Rovereto, TN, Italy

\section{ABSTRACT}

SVEP1, also known as Polydom, is a large extracellular mosaic protein with functions in protein interactions and adhesion. Since Svep1 knockout animals show severe edema and lymphatic system malformations, the aim of this study is to evaluate the presence of $S V E P 1$ variants in patients with lymphedema. We analyzed DNA from 246 lymphedema patients for variants in known lymphedema genes, 235 of whom tested negative and underwent a second testing for new candidate genes, including SVEP1, as reported here. We found three samples with rare heterozygous missense single-nucleotide variants in the SVEP1 gene. In one family, healthy members were found to carry the same variants and reported some subclinical edema. Based on our findings and a review of the literature, we propose SVEP1 as a candidate gene that should be sequenced in patients with lymphatic malformations, with or without lymphedema, in order to investigate and add evidence on its possible involvement in the development of lymphedema.

Keywords: $S V E P 1$, lymphedema, NGS, genetic diagnosis

Sushi, Von Willebrand Factor Type A, EGF and Pentraxin Domain Containing 1 (SVEP1), also known as Polydom or SELOB, is a protein encoded by the $S V E P 1$ gene on the long arm of chromosome 9 (9q31.3). SVEP1 is a large extracellular mosaic protein with complex structure. It consists of a signal peptide that regulates its secretion and various domains, including a pentraxin domain and a von Willebrand-factor-type-A domain, several EGF (epidermal growth factor) domains, and 34 complement control protein modules. When it was discovered, SVEP1 was suspected to be involved in hematopoiesis or in the immune system (1). Proteins structurally similar to SVEP1 are also extracellular and are known to play a role in protein-protein interactions and 


\begin{tabular}{|l|l|l|l|}
\hline \multicolumn{3}{|c|}{ Svep1-related Phenotype in Animal Models } \\
\hline Organism & Gene & Lethality & Lymphatic phenotype \\
\hline Mouse & Svep1 & $\begin{array}{l}\text { Svep1 } 1^{-/} \text {- death soon after birth } \\
(6,7)\end{array}$ & $\begin{array}{l}\text { Svep1/- severe edema, failure to form lymphatic } \\
\text { collecting vessels, impaired lymph uptake (6,7) }\end{array}$ \\
\hline Zebrafish & Svep1 & & $\begin{array}{l}\text { Svep1\% edema of various tissues, thoracic duct } \\
\text { malformations (6,7) }\end{array}$ \\
\hline
\end{tabular}

cell adhesion $(2,3)$.

The first suggestion that $S V E P 1$ might be important for lymphatic system function came in 2012, when Sato-Nishiuchi et al discovered its high affinity for integrin $\alpha 9 \beta 1$ (4). Integrin $\alpha 9(\operatorname{Ig} \alpha 9)$ is an adhesion receptor, important for lymphangiogenesis. Ig $\alpha 9$ deficient mice showed defects in lymphatic collecting vessel valve development and died in the first two weeks of life (5). Since SVEP1 is a ligand of $\operatorname{Ig} \alpha 9$ and binds it with high affinity, its role in the lymphatic system was suspected, but its function did not become clear until recently (Table 1).

Morooka et al (6) and Karpanen et al (7) used targeted deletion of the Svep1 gene in zebrafish and mice to demonstrate the role of this gene in lymphatic vascular remodeling. Svep $1^{-1}$ mice developed severe edema during gestation and died soon after birth. The differentiation of lymphatic endothelial cells (LECs) and the development of simple lymphatic structures were not impaired. In contrast, later development of the lymphatic system showed severe abnormalities. LECs failed to elongate, which led to abnormal cell structure; lymphatic collecting vessels failed to form; sprouting of lymphatic capillaries was also aberrant. The authors also demonstrated that these lymphatic system malformations prevented fluid uptake by lymphatic capillaries. Interestingly, these malformations were observed in many organs, including skin, heart and intestines, suggesting that Svep1 has a complex and ubiquitous role in lymphatic vessels and valve formation $(6,7)$.
In the zebrafish embryo, fish with nonsense mutations in Svep1 produced a truncated protein with a premature stop. Embryos developed edema of the eye, intestine, and heart (7). These embryos showed normal phenotype in early embryogenesis of the lymphatic system, but like mice, zebrafish too showed anomalous sprouting of lymphatic precursor cells $(6,7)$. Svep1 deletion thereby caused thoracic duct malformations. These findings, together with results obtained with the mouse model, show that Svep1 function is important for the normal development and maturation of lymphatic vessels and valves (8).

Lymphatic system malformations can cause pathological processes such as lymphedema, a condition resulting from impaired fluid homeostasis, insufficient fluid uptake by the lymphatic system or blockage of the lymph flow (9). Clinical features include tissue swelling, usually at the extremities, weight gain, fibrosis, and sometimes inflammation and pain (10). Although the genetic background of lymphedema has been studied in recent years, the underlying molecular mechanisms are not yet well understood.

In humans, $S V E P 1$ is not linked to any disease in OMIM and no association of lymphatic system disorders with SVEP1 function has been documented. Nonetheless, associations of variants in $S V E P 1$ and pathological processes were recently demonstrated in inflammatory diseases and infection management. Nakada et al (11) 
reported the deleterious role of a non-synonymous variant c.2080A $>C$ in septic shock. In a cohort of 520 septic patients, they found the $S V E P 1$ variant to be associated with more frequent organ failure and a higher risk of mortality within 28 days. The authors concluded that $S V E P 1$ was implicated in regulation of the leukocyte adhesion pathway (11). The $S V E P 1$ variant was also found in the GWAS study of lung function and asthma (12). Intronic variant rs1889321 was associated with alterations in lung function. The mechanisms underlying these associations are hypothetical and the exact function of the $S V E P 1$ gene in humans is still unclear.

Here we report a study of variants in $S V E P 1$ in patients with lymphedema. After testing a large series of lymphedema patients for known lymphedema-associated genes, we observed that $95.5 \%$ of our probands obtained negative results. We therefore decided to investigate possible new candidate genes, including $S V E P 1$, and to determine the genotypes of lymphedema patients with regard to these genes.

\section{MATERIALS AND METHODS}

\section{Clinical Evaluation}

Caucasian patients $(n=246)$ diagnosed with lymphedema in different hospitals across Italy were included retrospectively in the study. No consanguinity was reported in their families. Clinical diagnosis of lymphedema was according to accepted criteria and was confirmed by three-phase lymphoscintigraphy according to the protocol of Bourgeois. Genetic testing was performed on genomic DNA extracted from saliva or blood of the proband. Segregation analysis was performed on DNA extracted from saliva of the available probands' relatives.

\section{Genetic Analysis}

A custom-made oligonucleotide probe library was designed to capture all coding exons and flanking exon/intron boundaries $( \pm 15 \mathrm{bp})$ of 29 genes known to be associated with lymphedema. We added the candidate gene SVEP1 (OMIM 611691) to our panel.

DNA from the proband was analyzed. Variants of possible clinical significance (unknown significance and likely benign according to ACMG guidelines) were confirmed by bidirectional Sanger sequencing on a CEQ8800 Sequencer (Beckman Coulter). Segregation in available family members was performed by Sanger sequencing for variants identified in probands harboring heterozygous variants in $S V E P 1$.

We developed a Next-GenerationSequencing (NGS) protocol for the screening of the most frequently varied genes, namely ADAMTS3 (OMIM 605011), CELSR1 (OMIM 604523), EPHB4 (OMIM 600011), FAT4 (OMIM 612411), FLT4 (OMIM 136352), FOXC2 (OMIM 602402), GATA2 (OMIM 137295), GJA1 (OMIM 121014), GJC2 (OMIM 608803), HGF (OMIM 142409), KIF11 (OMIM 148760), PIEZO1 (OMIM 611184), PTPN14 (OMIM 603155), SOX18 (OMIM 601618), and VEGFC (OMIM 601528), including the candidate gene $S V E P 1$ (OMIM 611691).

We searched international databases dbSNP (www.ncbi.nlm.nih.gov/SNP/) and Human Gene Mutation Database professional (HGMD; http://www.biobase-international.com/product/hgmd) for all nucleotide changes. In silico evaluation of the pathogenicity of nucleotide changes in exons was performed using the Variant Effect Predictor tool (http://www.ensembl.org/Tools/VEP) and MutationTaster (http://www. Mutationtaster.org). Minor allele frequencies (MAF) were checked in the Genome Aggregation Database (gnomAD) (http://gnomad.broadinstitute.org/). All variants were evaluated according to American College of Medical Genetics and Genomics guidelines (13). Detailed pre-test genetic counseling was provided to all subjects, who were then invited to sign specific informed consent to use of their anonymized genetic results for research.

\section{In silico Analysis}

The primary amino acid sequence of SVEP1 in FASTA format (Table 3) was used 


\begin{tabular}{|c|c|c|c|c|c|c|c|c|c|c|}
\hline \multicolumn{11}{|c|}{$\begin{array}{c}\text { TABLE } 2 \\
\text { Clinical Features of Probands with SVEP1 Variants }\end{array}$} \\
\hline Family & Pedigree & Sex & $\begin{array}{l}\text { Age } \\
\text { (yr) }\end{array}$ & $\begin{array}{l}\text { Clinical } \\
\text { features }\end{array}$ & $\begin{array}{c}\text { Age of } \\
\text { onset }\end{array}$ & $\begin{array}{c}\text { Famil- } \\
\text { ial }\end{array}$ & $\begin{array}{c}\text { Variant } \\
\text { nomenclature } \\
\text { NM_153366 } \\
\text { NP_699197 }\end{array}$ & $\begin{array}{l}\text { Var- } \\
\text { some }\end{array}$ & dbSNP ID & $\begin{array}{l}\text { Frequency } \\
\text { (GnomAD) }\end{array}$ \\
\hline 1 & Proband & F & 29 & $\begin{array}{l}\text { lymphedema } \\
\text { of lower } \\
\text { limbs }\end{array}$ & $16 \mathrm{yr}$ & NO & $\begin{array}{l}\text { c.5561A }>\text { G } \\
\text { p.Glu1854Gly }\end{array}$ & VUS & rs749269448 & 0.0000121 \\
\hline 2 & Proband & $\mathrm{F}$ & 84 & $\begin{array}{l}\text { edema of } \\
\text { lower limbs }\end{array}$ & $35 \mathrm{yr}$ & NO & $\begin{array}{l}\text { c.8975A }>\text { T } \\
\text { p.Asn2992Ile }\end{array}$ & VUS & rs202217766 & 0.00004071 \\
\hline 3 & Proband & M & 29 & $\begin{array}{l}\text { lymphedema } \\
\text { of right lower } \\
\text { limb }\end{array}$ & $3 \mathrm{mo}$ & NO & $\begin{array}{l}\text { c. } 10450 C>T \\
\text { p.Arg3484Cys }\end{array}$ & VUS & rs189890058 & 0.00005337 \\
\hline 3 & Father & M & 63 & healthy & I & NO & wt & & & \\
\hline 3 & Mother & $\mathrm{F}$ & 54 & healthy & I & NO & $\begin{array}{l}\text { c. } 10450 \mathrm{C}>\mathrm{T} \\
\text { p.Arg3484Cys }\end{array}$ & & & \\
\hline 3 & Brother & M & 25 & healthy & I & NO & $\begin{array}{l}\text { c. } 10450 C>T \\
\text { p.Arg3484Cys }\end{array}$ & & & \\
\hline
\end{tabular}

as target to search the Swiss model template library (SMTL) version 2019-10-24 and Protein Data Bank (PDB) release 2019-10-18 (14) for matching evolution-related structures by means of BLAST (Basic Local Alignment Search Tool) (15) and HHBlits (16). Models were built based on target-template alignment using ProMod3 of the SWISS-MODEL server (17). Coordinates conserved between the target and the template were copied from the template to the model. Insertions and deletions were remodeled using a fragment library. Side chains were then rebuilt. Finally, the geometry of the resulting model was regularized by CHARMM27 force field (18). In the case of failure of loop modeling with ProMod3, an alternative model was built with ProMod-II (19). Global and per-residue model quality was assessed using the QMEAN scoring function (20). BioVia Discovery Studio Visualizer ver17.2 (21) was used to visualize the modeled protein, to vary the targeted amino acids and to analyze molecular level interactions.

\section{RESULTS}

\section{Clinical Features}

We identified rare variants in $S V E P 1$ in three of the 235 lymphedema patients who tested negative for known lymphedema genes (22). Available family members were also tested for variants identified in the probands. Clinical features of all probands carrying SVEP1 variants are summarized in Table 2.

The first proband, female, 29 years, was diagnosed with lymphedema of the lower limbs at age 16. This case is sporadic and no other family members were tested. The proband carries a heterozygous missense variant NM_153366.3:c.5561A $>\mathrm{G}$ in the $S V E P 1$ gene that causes a change of Glutamic Acid in position 1854 to Glycine. In dbSNP this allele is known as rs749269448 and its frequency is 0.00001226 according to GnomAD.

The second proband, female, 84 years, was diagnosed at age 35 with edema of the lower limbs. This is a sporadic case and no other family members were tested. The proband carries a heterozygous missense SVEP1 variant NM_153366.3:c.8975A > T 
TABLE 3

Primary Amino Acid Sequences for which Templates were Searched and Models were Built

MWPRLAFCCWGLALVSGWATFQQMSPSRNFSFRLFPETAPGAPGSIPAPPAPGDEAAGSRVERLGQA FRRRVRLLRELSERLELVFLVDDSSSVGEVNFRSELMFVRKLLSDFPVVPTATRVAIVTFSSKNYVVPR VDYISTRRARQHKCALLLQEIPAISYRGGGTYTKGAFQQAAQILLHARENSTKVVFLITDGYSNGGDP RPIAASLRDSGVEIFTFGIWQGNIRELNDMASTPKEEHCYLLHSFEEFEALARRALHEDLPSGSFIQDD MVHCSYLCDEGKDCCDRMGSCKCGTHTGHFECICEKGYYGKGLQYECTACPSGTYKPEGSPGGISS CIPCPDENHTSPPGSTSPEDCVCREGYRASGQTCELVHCPALKPPENGYFIQNTCNNHFNAACGVRC HPGFDLVGSSIILCLPNGLWSGSESYCRVRTCPHLRQPKHGHISCSTREMLYKTTCLVACDEGYRLEG SDKLTCQGNSQWDGPEPRCVERHCSTFQMPKDVIISPHNCGKQPAKFGTICYVSCRQGFILSGVKEM LRCTTSGKWNVGVQAAVCKDVEAPQINCPKDIEAKTLEQQDSANVTWQIPTAKDNSGEKVSVHVHP AFTPPYLFPIGDVAIVYTATDLSGNQASCIFHIKVIDAEPPVIDWCRSPPPVQVSEKVHAASWDEPQFS DNSGAELVITRSHTQGDLFPQGETIVQYTATDPSGNNRTCDIHIVIKGSPCEIPFTPVNGDFICTPDNT GVNCTLTCLEGYDFTEGSTDKYYCAYEDGVWKPTYTTEWPDCAKKRFANHGFKSFEMFYKAARCD DTDLMKKFSEAFETTLGKMVPSFCSDAEDIDCRLEENLTKKYCLEYNYDYENGFAIGPGGWGAANR LDYSYDDFLDTVQETATSIGNAKSSRIKRSAPLSDYKIKLIFNITASVPLPDERNDTLEWENQQRLLQTL ETITNKLKRTLNKDPMYSFQLASEILIADSNSLETKKASPFCRPGSVLRGRMCVNCPLGTYYNLEHFT CESCRIGSYQDEEGQLECKLCPSGMYTEYIHSRNISDCKAQCKQGTYSYSGLETCESCPLGTYQPKFG SRSCLSCPENTSTVKRGAVNISACGVPCPEGKFSRSGLMPCHPCPRDYYQPNAGKAFCLACPFYGTTP FAGSRSITECSSFSSTFSAAEESVVPPASLGHIKKRHEISSQVFHECFFNPCHNSGTCQQLGRGYVCLCP LGYTGLKCETDIDECSPLPCLNNGVCKDLVGEFICECPSGYTGQRCEENINECSSSPCLNKGICVDGV AGYRCTCVKGFVGLHCETEVNECQSNPCLNNAVCEDQVGGFLCKCPPGFLGTRCGKNVDECLSQPC KNGATCKDGANSFRCLCAAGFTGSHCELNINECQSNPCRNQATCVDELNSYSCKCQPGFSGKRCETE QSTGFNLDFEVSGIYGYVMLDGMLPSLHALTCTFWMKSSDDMNYGTPISYAVDNGSDNTLLLTDYN GWVLYVNGREKITNCPSVNDGRWHHIAITWTSANGIWKVYIDGKLSDGGAGLSVGLPIPGGGALVL GQEQDKKGEGFSPAESFVGSISQLNLWDYVLSPQQVKSLATSCPEELSKGNVLAWPDFLSGIVGKVKI DSKSIFCSDCPRLGGSVPHLRTASEDLKPGSKVNLFCDPGFQLVGNPVQYCLNQGQWTQPLPHCERIS CGVPPPLENGFHSADDFYAGSTVTYQCNNGYYLLGDSRMFCTDNGSWNGVSPSCLDVDECAVGSDC SEHASCLNVDGSYICSCVPPYTGDGKNCAEPIKCKAPGNPENGHSSGEIYTVGAEVTFSCQEGYQLM GVTKITCLESGEWNHLIPYCKAVSCGKPAIPENGCIEELAFTFGSKVTYRCNKGYTLAGDKESSCLAN SSWSHSPPVCEPVKCSSPENINNGKYILSGLTYLSTASYSCDTGYSLQGPSIIECTASGIWDRAPPACHL VFCGEPPAIKDAVITGNNFTFRNTVTYTCKEGYTLAGLDTIECLADGKWSRSDQQCLAVSCDEPPIVD HASPETAHRLFGDIAFYYCSDGYSLADNSQLLCNAQGKWVPPEGQDMPRCIAHFCEKPPSVSYSILES VSKAKFAAGSVVSFKCMEGFVLNTSAKIECMRGGQWNPSPMSIQCIPVRCGEPPSIMNGYASGSNYSF GAMVAYSCNKGFYIKGEKKSTCEATGQWSSPIPTCHPVSCGEPPKVENGFLEHTTGRIFESEVRYQC NPGYKSVGSPVFVCQANRHWHSESPLMCVPLDCGKPPPIQNGFMKGENFEVGSKVQFFCNEGYELV GDSSWTCQKSGKWNKKSNPKCMPAKCPEPPLLENQLVLKELTTEVGVVTFSCKEGHVLQGPSVLKC LPSQQWNDSFPVCKIVLCTPPPLISFGVPIPSSALHFGSTVKYSCVGGFFLRGNSTTLCQPDGTWSSPLP ECVPVECPQPEEIPNGIIDVQGLAYLSTALYTCKPGFELVGNTTTLCGENGHWLGGKPTCKAIECLKP KEILNGKFSYTDLHYGQTVTYSCNRGFRLEGPSALTCLETGDWDVDAPSCNAIHCDSPQPIENGFVEG ADYSYGAIIIYSCFPGFQVAGHAMQTCEESGWSSSIPTCMPIDCGLPPHIDFGDCTKLKDDQGYFEQE DDMMEVPYVTPHPPYHLGAVAKTWENTKESPATHSSNFLYGTMVSYTCNPGYELLGNPVLICOEDG TWNGSAPSCISIECDLPTAPENGFLRFTETSMGSAVQYSCKPGHILAGSDLRLCLENRKWSGASPRCE AISCKKPNPVMNGSIKGSNYTYLSTLYYECDPGYVLNGTERRTCQDDKNWDEDEPICIPVDCSSPPVS ANGQVRGDEYTFQKEIEYTCNEGFLLEGARSRVCLANGSWSGATPDCVPVRCATPPQLANGVTEGL DYGFMKEVTFHCHEGYILHGAPKLTCQSDGNWDAEIPLCKPVNCGPPEDLAHGFPNGFSFIHGGHIQ YQCFPGYKLHGNSSRRCLSNGSWSGSSPSCLPCRCSTPVIEYGTVNGTDFDCGKAARIQCFKGFKLLG LSEITCEADGQWSSGFPHCEHTSCGSLPMIPNAFISETSSWKENVITYSCRSGYVIQGSSDLICTEKGV WSQPYPVCEPLSCGSPPSVANAVATGEAHTYESEVKLRCLEGYTMDTDTDTFTCQKDGRWFPERISC SPKKCPLPENITHILVHGDDFSVNRQVSVSCAEGYTFEGVNISVCQLDGTWEPPFSDESCSPVSCGKPE SPEHGFVVGSKYTFESTIIYQCEPGYELEGNRERVCQENRQWSGGVAICKETRCETPLEFLNGKADIE NRTTGPNVVYSCNRGYSLEGPSEAHCTENGTWSHPVPLCKPNPCPVPFVIPENALLSEKEFYVDQNVS IKCREGFLLQGHGIITCNPDETWTQTSAKCEKISCGPPAHVENAIARGVHYQYGDMITYSCYSGYMLE GFLRSVCLENGTWTSPPICRAVCRFPCQNGGICQRPNACSCPEGWMGRLCEEPICILPCLNGGRCVAP YQCDCPPGWTGSRCHTAVCQSPCLNGGKCVRPNRCHCLSSWTGHNCSRKRRTGF 

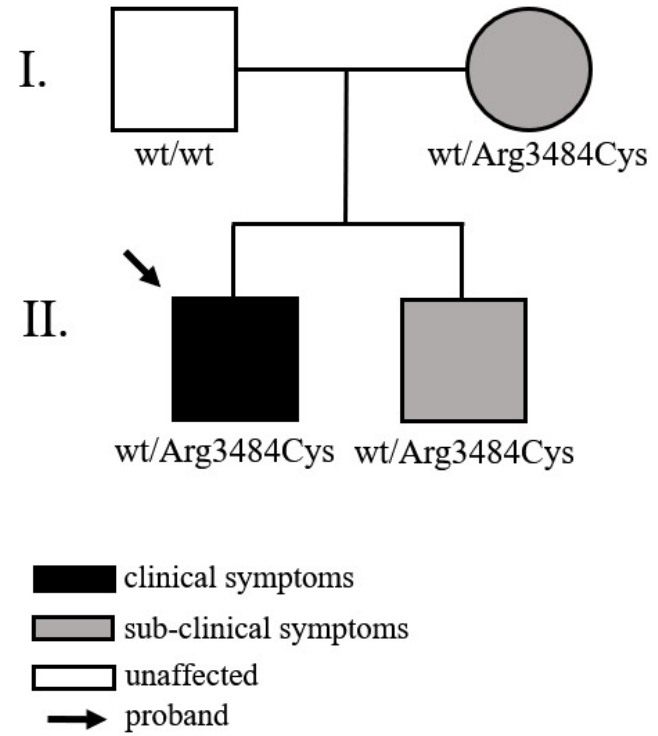

Fig. 1. Pedigree of Family 3. The proband carries a heterozygous variant NP_699197.3:p.Arg3484Cys and has lymphedema. The mother and brother have the same variant. Although they are lymphedema free, both have symptoms of subclinical intermittent edema. The father does not carry the SVEP1 variant.

in which Asparagine 2992 is replaced by Isoleucine. The dbSNP ID of this variant is rs202217766 and GnomAD reports an allele frequency of 0.00004071 .

In the third family, the proband, male, age 29 years, was diagnosed with juvenile lymphedema of the right lower limb.

Verrucous hyperplasia of the second right foot valgus was the first sign of the disease but the lymphedema progressed in right lower limb lymphedema to a disabling stage of the limb at this moment. We identified a heterozygous missense single nucleotide variant NM_15336 6.3:c.10450C $>\mathrm{T}$, which at protein level changes Arginine in position 3484 to Cysteine. This $S V E P 1$ variant classified according to ACGM as variant with unknown significance is known in the dbSNP database as rs 1898900 58 and has a reported frequency of 0.00005337 (GnomAD). Genetic testing of available family members revealed the same variant in the mother and brother but not the father (Fig. 1). The mother and brother do not manifest lymphedema. To determine possible lymphatic system malformations, the mother and brother underwent clinical evaluation, which showed slight manifestation of sub-clinical intermittent edema.

\section{In silico Analysis, Template Selection and Model Building}

A template search with BLAST and HHBlits was performed against the SWISSMODEL template library (SMTL, last update: 2019-10-24, last included PDB release: 201910-18). A total of 797 templates were found to match with different sequence identity and quality percentages. Details of the top ten templates are shown in Table 4.

Based on the percentage of sequence identity, similarity, and best quality square, the 5o32.1.C chain was selected to align the template and query sequences for model building. The model is shown in Fig. 2 . We entered the model in Discovery studio visualizer to generate Glu1854Gly, and Asn2992Ile versions of its structure. During the modeling studies, due to lack of the template at some regions, we were unable to model the Arg3484Cys. Molecular level interaction analysis between native/mutant residues was performed (for snapshots see Figs. 3-4). Details of the residues involved in interactions, the types of bond they formed and bond lengths in Angstrom units are shown in Tables 5-6. In both cases (Glu1854Gly and Asn2992Ile), the mutant residue loses the interaction with the residue in the neighborhood. Indeed, the substitution Glu1854Gly or Asn2992Ile alter substantially the polarity of the residue, from a polar amino acid (Glu and Asn) to a non-polar one (Gly and Ile). In the third substitution (Arg3484Cys), there is a change from a positively charged aminoacid (Arg) to a non polar one (Cys).

\section{DISCUSSION AND CONCLUSIONS}

The lymphatic system is crucial for the human body because it provides immune surveillance and maintains fluid homeostasis. The lymphatic network is composed of 


\section{TABLE 4}

\section{Top Ten Models for 3D Modeling of SVEP1 Structure}

\begin{tabular}{|l|l|l|l|l|l|l|l|l|l|}
\hline Template & $\begin{array}{l}\text { Seq } \\
\text { Identity }\end{array}$ & Oligo-state & QSQE & Found by & Method & Resolution & $\begin{array}{l}\text { Seq } \\
\text { similarity }\end{array}$ & Coverage & Description \\
\hline 5032.1.C & 30.09 & monomer & - & BLAST & X-ray & $4.21 \AA$ & 0.37 & 0.09 & $\begin{array}{l}\text { Complement } \\
\text { factor H }\end{array}$ \\
\hline 5032.1.C & 31.21 & monomer & - & BLAST & X-ray & $4.21 \AA$ & 0.37 & 0.09 & $\begin{array}{l}\text { Complement } \\
\text { factor H }\end{array}$ \\
\hline 5035.1.C & 30.09 & monomer & - & BLAST & X-ray & $4.20 \AA$ & 0.37 & 0.09 & $\begin{array}{l}\text { Complement } \\
\text { factor H }\end{array}$ \\
\hline 5032.1.H & 31.21 & monomer & 0.37 & BLAST & X-ray & $4.21 \AA$ & 0.37 & 0.09 & $\begin{array}{l}\text { Complement } \\
\text { factor H }\end{array}$ \\
\hline 5035.1.C & 30.38 & monomer & 0.37 & BLAST & X-ray & $4.20 \AA$ & 0.37 & 0.09 & $\begin{array}{l}\text { Complement } \\
\text { factor H }\end{array}$ \\
\hline 5032.1.H & 30.38 & monomer & - & BLAST & X-ray & $4.21 \AA$ & 0.37 & 0.09 & $\begin{array}{l}\text { Complement } \\
\text { factor H }\end{array}$ \\
\hline 5032.1.C & 30.38 & monomer & - & BLAST & X-ray & $4.21 \AA$ & 0.37 & 0.09 & $\begin{array}{l}\text { Complement } \\
\text { factor H }\end{array}$ \\
\hline 5035.1.C & 31.07 & monomer & - & BLAST & X-ray & $4.20 \AA$ & 0.37 & 0.09 & $\begin{array}{l}\text { Complement } \\
\text { factor H }\end{array}$ \\
\hline 5032.1.C & 31.07 & monomer & - & BLAST & X-ray & $4.21 \AA$ & 0.37 & 0.09 & $\begin{array}{l}\text { Complement } \\
\text { factor H }\end{array}$ \\
\hline 5032.1.H & 31.07 & monomer & - & BLAST & X-ray & $4.21 \AA$ & 0.37 & 0.09 & $\begin{array}{l}\text { Complement } \\
\text { factor H }\end{array}$ \\
\hline
\end{tabular}
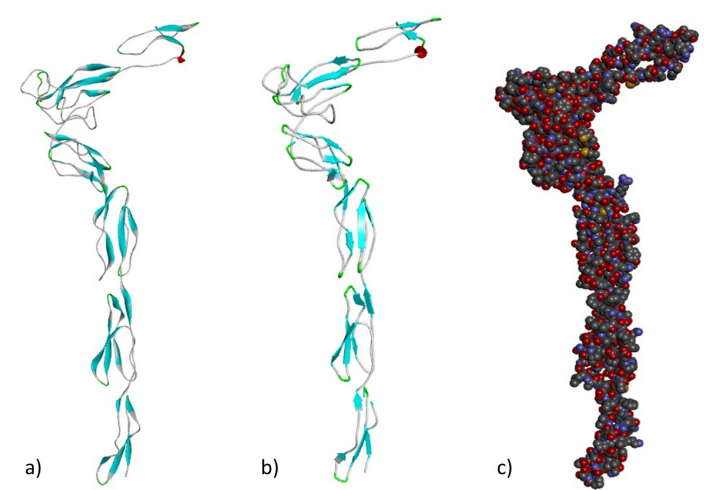

Fig. 2. Modeled structure of SVEP1 gene in a) ribbon b) schematic and c) CPK view. Cyan regions are beta sheets, white represents loops and red represents alpha helices. In CPK view, carbon is grey, oxygen red, nitrogen blue, hydrogen white, chlorine green, sulfur yellow, phosphorus orange, and iron is reddish brown.

different parts, including lymphatic capillaries, collecting vessels with valves, lymph nodes, trunks, and ducts (23). When the lymphatic system is not functioning well, there is poor drainage of fluid, which accumulates in the tissues. This may lead to lymphedema and progressive disease with edema, inflammation, and fibrosis.

A panel of 29 genes is used for genetic testing in cases of lymphedema (22), but the genetic background of lymphedema is not yet well understood. When we used this panel to test 246 Italian lymphedema patients, we found that 235 were negative for known lymphedema genes. We are evidently far from identifying all the genes that may have variants involved in lymphedema. This demonstrates the need for new candidate genes. We therefore tested our cohort for variants in possible new candidate genes, including $S V E P 1$, described in this paper.

$S V E P 1$ encodes an extracellular multidomain protein believed to have a function in protein interactions and adhesion (1). It contains multiple EGF domains, which are well conserved and are found in proteins 


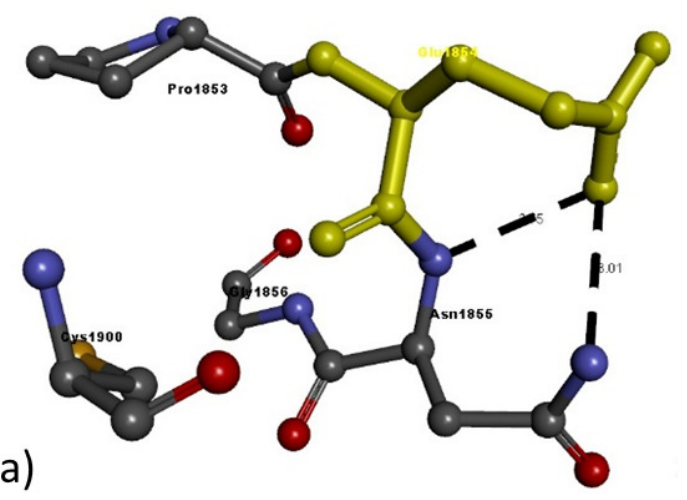

b)

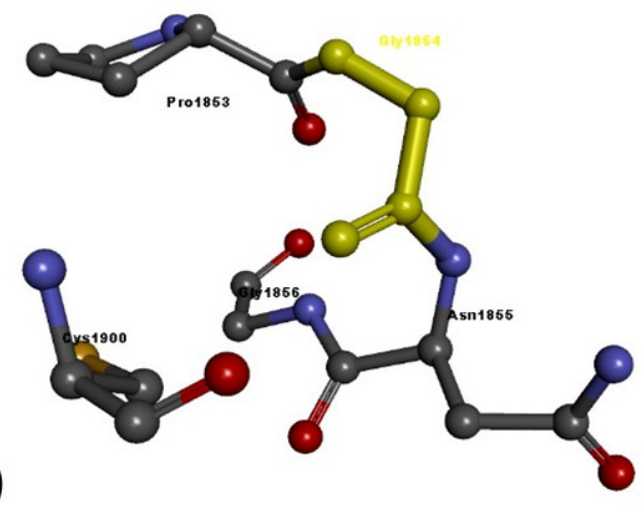

Fig. 3. Molecular interactions of a) Glu1854 and b) Gly1854 (in yellow, variant identified in the first proband) residue of SVEP1 modeled protein with adjacent residues.
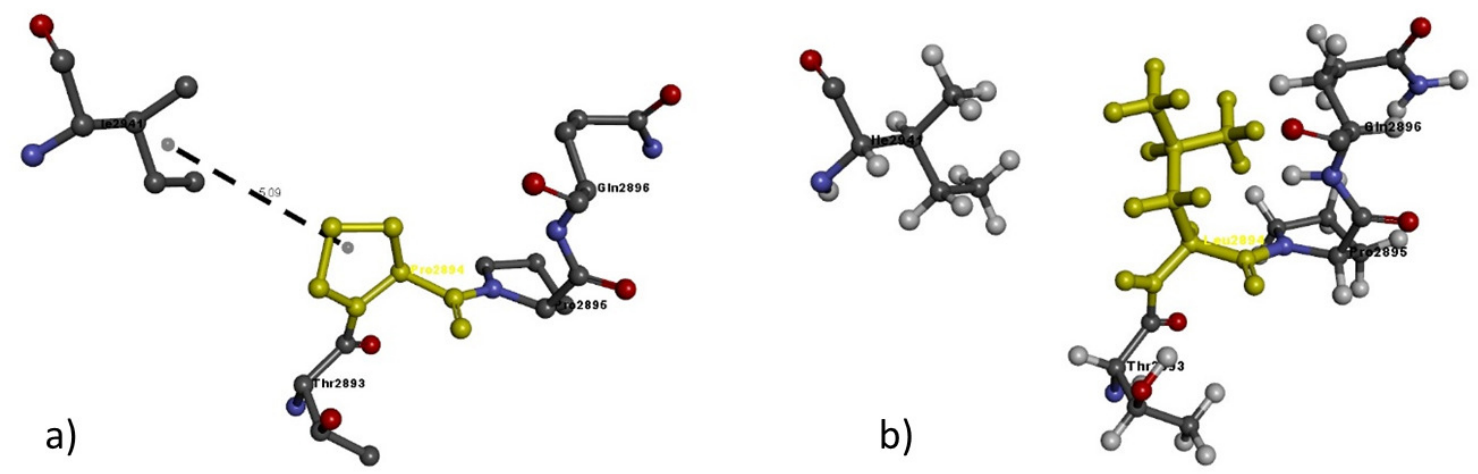

Fig. 4. Molecular interactions of a) Pro2894 and b) Leu2894 (in yellow, variant identified in the second proband) of the modeled SVEP1 protein with adjacent residues

\section{TABLE 5}

Details of Molecular Interactions of a) Glu1854 and b) Gly1854 of the Modeled SVEP1 Protein with Adjacent Residues. This Variant was Screened in the DNA of the First Proband.

\begin{tabular}{|c|c|c|c|c|c|}
\hline S.No & Variant & $\begin{array}{l}\text { Amino } \\
\text { acid }\end{array}$ & $\begin{array}{l}\text { Molecular interactions } \\
\text { observed }\end{array}$ & $\begin{array}{l}\text { Bond length } \\
\text { in Angstroms }\end{array}$ & Bond type \\
\hline 1. & Glu1854Gly & Glu1854 & Asn1855:N - Glu1854:O & 2.75 & H-bond \\
\hline 2. & & & Asn1855:N - Glu1854:O & 3.01 & H-bond \\
\hline 3. & & Gly1854 & No bonds & - & - \\
\hline
\end{tabular}


TABLE 6

Details of Molecular Interactions of a) Pro2894 and b) Leu2894 of the Modeled SVEP1 Protein with Adjacent Residues. This Variant was Detected in Lymphedema Patient 2.

\begin{tabular}{|c|l|l|l|l|l|}
\hline S.No & Mutation & Amino acid & $\begin{array}{l}\text { Molecular interactions } \\
\text { observed }\end{array}$ & $\begin{array}{l}\text { Bond length in } \\
\text { Angstroms }\end{array}$ & Bond type \\
\hline 1. & \multirow{2}{*}{ Pro2894Leu } & Pro2894 & Pro2894 - Ile2941 & 5.09 & H-bond \\
\cline { 4 - 6 } & & Leu2894 & No bonds & - & - \\
\hline 2. & & & & \\
\hline
\end{tabular}

with various biological functions, such as cell fate determination, fibrinolysis, clotting and cell migratory behavior (3).

Studies of Svep1-deficient mice and zebrafish demonstrated the importance of Svep1 in the development and maturation of the lymphatic system $(6,7)$. Svep1-deficiency in mice results in death soon after birth. Svep1-null mice developed simple primary lymphatics early in embryogenesis, but the lymphatic system failed to mature and form more complex structures. Lymphatic collectors did not form, and Svep $1^{-1-}$ mice showed severe edema $(6,7)$. The authors also demonstrated that these lymphatic malformations prevented fluid uptake (6).

Comparable observations have been made in zebrafish, where Svep1-deficient fish developed edema in many organs. Early formation of the lymphatic system during embryogenesis appeared normal, but lymphatic precursor cells failed to sprout, which caused various malformations. Svep ${ }^{-/-}$zebrafish also showed abnormal thoracic ducts $(6,7)$. Lymphatic ducts ensure the final stage of lymph circulation, being responsible for returning the lymph to the bloodstream (23). Findings in animal models clearly show the importance of Svep1 in the lymphatic system and the consequences of Svep1 dysfunction.

Interestingly, despite its discernible function in the lymphatic system, $S V E P 1$ is not expressed by lymphatic endothelial cells but rather by a closely related cell type in the vicinity of lymphatic precursor cells (8). The identity of this cell type has not yet been determined, but it is suggested to be specific to the lymphatic system and may be required for the patterning of lymphatic vessels (6).

$S V E P 1$ variants have not yet been linked to diseases of lymphatic origin in humans, although they have been implicated in various inflammatory diseases $(11,12)$. Inflammatory processes are also common in lymphedema patients, since the lymphatic system plays a crucial role in immune maintenance $(24,25)$.

In our study, three out of 235 lymphedema patients $(3 / 235 ; 1.2 \%)$ carried a $S V E P 1$ variant. Two probands are females and one is a male. All probands carry heterozygous, missense variants and all cases are sporadic. Age at onset of lymphedema was before 35 years of age and in all cases, one or both lower limbs were affected.

In family 3 , other family members were also tested for subclinical signs. In this family, two unaffected family members carry the same $S V E P 1$ variant as the respective probands. They are not affected with lymphedema, but they have subclinical symptoms of intermittent edema.

Bioinformatic analysis of the effect of $S V E P 1$ variants on overall protein structure was performed. Our in silico analysis showed that SVEP1 structure with Asn2992 has one interaction whereas Ile2992 shows two. In the case of Glu1854Gly, there is a major difference in interactions, the original showing two interactions and the mutant showing none. It can be concluded that overall protein conformation is somehow altered by these differences in interactions with nearby residues which could lead to functional defects in the protein.

In conclusion, the literature indicates that $S V E P 1$ is an important player in the development of lymphatic vasculature and is 
indispensable for normal drainage of proteinrich fluid from the tissues. We identified SVEP1 variants in 3 lymphedema patients, of which in two family members that carried the SVEP1 variants showed manifestation of subclinical intermittent edema. We therefore suggest that further studies are needed to increase the cohort of patients screened for variant in $S V E P 1$ in order to add evidence of its possible involvement in lymphedema.

\section{ACKNOWLEDGMENTS}

We would like to thank Helen Ampt for the English language editing. This work was supported by funding from the Provincia Autonoma di Trento within the initiative LP 6/99 (dgp 1045/2017).

\section{CONFLICT OF INTEREST AND DISCLOSURE}

The authors declare no competing financial interests exist.

\section{REFERENCES}

1. Gilgès, D, MA Vinit, I Callebaut, et al: Polydom: A secreted protein with pentraxin, complement control protein, epidermal growth factor and von Willebrand factor $\mathrm{A}$ domains. Biochem. J. 352 (2000), Pt 1:49-59.

2. Doolittle, RF: The multiplicity of domains in proteins. Annu. Rev. Biochem. 64 (1995), 287-314.

3. Bork, P, AK Downing, B Kieffer, ID Campbell: Structure and distribution of modules in extracellular proteins. Q. Rev. Biophys. 29 (1996), 119-167.

4. Sato-Nishiuchi, R, I Nakano, A Ozawa, et al: Polydom/SVEP1 is a ligand for integrin $\alpha 9 \beta 1$. J. Biol. Chem. 287 (2012), 25615-25630.

5. Bazigou, E, S Xie, C Chen, et al: Integrin- $\alpha 9$ is required for fibronectin matrix assembly during lymphatic valve morphogenesis. Dev. Cell 17 (2009), 175-186.

6. Morooka, N, S Futaki, R Sato-Nishiuchi, et al: Polydom is an extracellular matrix protein involved in lymphatic vessel remodeling. Circ. Res. 120 (2017), 1276-1288.

7. Karpanen, T, Y Padberg, SA Van De Pavert, et al: An evolutionarily conserved role for
Polydom/SVEP1 during lymphatic vessel formation. Circ. Res. 120 (2017), 1263-1275.

8. Lawson, ND: A new conserved player in lymphatic morphogenesis. Circ. Res. 120 (2017), 1216-1218.

9. Liu, NF: Truncular lymphatic malformation (LM): Primary lymphedema. In: Congenital Vascular Malformations. Kim, Y-W, BB Lee, WF Yakes, Y-S Do (Eds.). (2017), 121-128.

10. Michelini, S, M Cardone, $P$ Maltese, et al: Primary lymphedema and genetic implications. EuroBiotech J. 1(s2) (2017), 144-146.

11. Nakada, TA, JA Russell, JH Boyd, et al: Identification of a nonsynonymous polymorphism in the $S V E P 1$ gene associated with altered clinical outcomes in septic shock. Crit. Care Med. 43 (2015), 101-108.

12. Imboden, M, E Bouzigon, I Curjuric, et al: Genome-wide association study of lung function decline in adults with and without asthma. J. Allergy Clin. Immunol. 129 (2012), 1218-1228.

13. Richards, $\mathrm{S}, \mathbf{N}$ Aziz, $\mathrm{S}$ Bale, et al: Standards and guidelines for the interpretation of sequence variants: $A$ joint consensus recommendation of the American College of Medical Genetics and Genomics and the Association for Molecular Pathology. Genet. Med. 17 (2015), 405-424.

14. Berman, HM, J Westbrook, Z Feng, et al: The Protein Data Bank. Nucleic Acids Res. 28 (2000), 235-242.

15. Camacho, C, G Coulouris, V Avagyan, et al: BLAST+: Architecture and applications. BMC Bioinformatics 10 (2009), 1-9.

16. Remmert, M, A Biegert, A Hauser, et al: Lightning-fast iterative protein sequence searching by HMM-HMM alignment. Nat. Methods 9 (2012), 173-175.

17. Waterhouse, A, M Bertoni, S Bienert, et al: SWISS-MODEL: Homology modelling of protein structures and complexes. Nucleic Acids Res. 46(W1) (2018),W296-W303.

18. Mackerell, AD, M Feig, CL Brooks: Extending the treatment of backbone energetics in protein force fields: Limitations of gas-phase quantum mechanics in reproducing protein conformational distributions in molecular dynamics simulation. J. Comput. Chem. 25 (2004), 1400-1415.

19. Guex, N, MC Peitsch, T Schwede: Automated comparative protein structure modeling with SWISS- MODEL and Swiss-PdbViewer: 
historical perspective. Electrophoresis 30(SUPPL. 1) (2009), 162-173.

20. Benkert P, Biasini M, Schwede T: Toward the estimation of the absolute quality of individual protein structure models. Bioinformatics 27 (2011), 343-350.

21. Studio, BD. Dassault Systèmes BIOVIA. Discovery Studio Modeling Environment [Internet] (2016).

22. Michelini, S, S Paolacci, E Manara, et al: Genetic tests in lymphatic vascular malformations and lymphedema. J. Med. Genet. 55 (2018), 222-232.

23. Swartz, MA: The physiology of the lymphatic system. Adv. Drug Deliv. Rev. 50 (2001), 320.
24. Ghanta, S, DA Cuzzone, JS Torrisi, et al: Regulation of inflammation and fibrosis by macrophages in lymphedema. Am. J. Physiol. - Heart Circ. Physiol. 308 (2015), H1065H1077.

25. Dayan, JH, CL Ly, RP Kataru, BJ Mehrara: Lymphedema: Pathogenesis and novel therapies. Annu. Rev. Med. 69 (2018), 263276.

\author{
Astrit Dautaj, MD \\ EBTNA-Lab \\ Via delle Maioliche 57 D \\ Rovereto, TN, Italy \\ E-mail: astrit.dautaj@assomagi.org
}

